\title{
IMPLEMENTATION OF E-LEARNING AS AN INTEGRAL PART OF THE EDUCATIONAL PROCESS
}

\author{
Nataliia Havryliuk \\ Vinnytsia Institute of Trade and Economics of KNUTE, Ukraine \\ Olga Osaulchyk \\ Vinnytsia Institute of Trade and Economics of KNUTE, Ukraine \\ Larysa Dovhan \\ Vinnytsia Institute of Trade and Economics of KNUTE, Ukraine \\ Nataliia Bondar \\ Vinnytsia Institute of Trade and Economics of KNUTE, Ukraine
}

\begin{abstract}
The paper aims to examine current tendencies in implementing e-learning as an integral part of the educational process. The relevance of e-learning as an advanced and effective technology of intensification and digitalization of teaching is proved. Theoretical research methods are used to analyze scientific, pedagogical and psychological researches on the issues of using e-learning while teaching students. Synthesis and analysis refine the conceptual apparatus of the study. Methods of induction and deduction have been used to establish links between basic concepts and their peculiarities, the research method has been applied to formulate conclusions of the study, the prognostic method has helped to substantiate innovations in the educational process with the use of e-learning. Scientific views have been analyzed regarding the definition of e-learning. A scientific approach to implementing $e$ learning in educational institutions has been carried out. Modern methods forms of e-learning have been identifies and their classification into person-oriented and group-oriented ones have been developed depending on the target audience and particular objectives of the class. It is resulted that blended e-learning can be considered as the most suitable and farsighted one. Within our investigation it has been concluded that e-learning is an effective and innovative educational technology that can improve the teaching process in educational institutions. It is been established that implementation of innovative e-learning methods at the foreign language classes have increased foreign language proficiency of students, let us involve all the group into active work, provided the best conditions for gaining listening and reading skills, increased motivation for learning, promoted personal development of students, made the teaching process student-centered.
\end{abstract}

Keywords: e-learning educational process, information technologies, communication technologies forms of e-learning, methods of e-learning, blended e-learning. 
Havryliuk et al., 2020. Implementation of E-Learning as an Integral Part of the Educational Process

\section{Introduction}

Nowadays, the Internet is becoming one of the most important ways of obtaining and distributing information for both students and teachers. Advanced online technologies enable people to share ideas, provide the environment for creative collaboration and develop a collective intelligence. Implementation of up-to-date educational digital techniques and the use of electronic didactic tools make the teaching practice much more effective.

Availability of the Internet let the Universities deliver educational courses and resources making traditional teaching methods less popular with the students. Conventional educational technologies do not always meet modern requirements, since some traditional elements are already outdated, e.g. higher education as a form of lifelong learning, a teacher-centered approach, structure of the academic courses, some forms of the educational process organization, books as the main tool of obtaining information.

Electronic pedagogy as a field of general pedagogical science that studies teaching organized through the Internet or online instruction is being developed in response to the needs of the modern digital generation. E-learning has originated as a name for the advanced developments provided in education through the application of Information and Communication Technologies (ICT) and the Internet (Tibaná-Herrera et al., 2018). However, the concept of epedagogy has no single definition. In our opinion, the most general is the one that defines pedagogy as the scientific study, description and prediction of processes in any electronic educational environment (Kostikova, 2015, p. 9).

Basic principles of e-pedagogy have been outlined by the researchers. According to them, e-learning is aimed to ensure frequent and regular contact between the teacher and students as well as among students, develop reciprocity and cooperation among students, provide students more with feedback than evaluation, create positive and supportive learning environment, respect the talents and learning styles in creating learning activities and materials, provide students with clear expectations from the beginning of the course, provide teachers with proper training for e-learning (Simuth \& Sarmany-Schuller, 2012).

Nowadays, the terms "e-textbook", "e-education", "e-learning” are being widely used. Electronic didactics in the electronic educational environment is evolving fast enough due availability of the digital teaching techniques. Therefore, e-learning is becoming an advanced and effective technology of intensification and digitalization of teaching.

The paper aims to specify the term "e-learning" as an integral part of the process of teaching foreign languages, outline and classify basic methods of elearning and provide effective practical techniques for implementing e-learning in the process of teaching "Business Foreign Language" . 


\section{Research methods}

Theoretical research methods are used to analyze scientific, pedagogical and psychological researches on the issues of using e-learning while teaching "Business Foreign Language" to students. Synthesis and analysis refine the conceptual apparatus of the study. Methods of induction and deduction have been used to establish links between basic concepts and their peculiarities, the research method has been applied to formulate conclusions of the study, the prognostic method has helped to substantiate innovations in the educational process with the use of e-learning.

\section{Results and discussion}

There are many definitions of e-learning, but it is controversial to find a common one. Some scholars describe e-learning as online learning for students who learn the material at a distance, while others view e-learning as a specially created learning environment that functions to spread and enhance collaboration. Is e-learning the online learning or the blended learning version or the distance learning? Some researchers consider e-learning more than online training courses. For example, Oblinger \& Hawkins (2005) state that e-learning originates from online technology courses and becomes an independent course that is provided with continuous access at any time from anywhere.

E-learning is also related to learning using information and communication technologies that provide access to e-learning. Abbad, Morris, \& Nahlik (2009) interpret e-learning more widely, that is, the process of learning online. Most researchers use the term "e-learning" speaking about distance and blended learning (Dewey \& DeBlois, 2006).

However, in our opinion, distance and blended learning are two different and independent teaching techniques, although they have similar features.

Reviewing the literature, Liu and Wang (2009) have found that the Internet is the basis for e-learning and is a resource for the exchange and distribution of information, providing flexibility for learning and helping to overcome problems connected with distance and time. Scientists have the opinion that the development of the Internet has turned distance learning into e-learning (Liu \& Wang, 2009).

Modern scholars identify e-learning as a revolutionary approach to learning (Jennex, 2005; Tao, Yeh, \& Sun, 2006). This is an innovative environment that enables students at universities to receive individualized training. This fact promotes effective interaction and collaboration among students and in the teacher-student mode. Liaw \& Huang (2007) focus on the maintenance, low cost, quality and rapidity of e-learning. It is clear that e-learning enables students of 
Havryliuk et al., 2020. Implementation of E-Learning as an Integral Part of the Educational Process

higher education to receive education, achieve their goals, and make their own careers without necessarily attending the university. Thus, there is no commonly accepted definition.

Somayeh et al. (2016) believe that e-learning belongs to a system of work when the teacher and the student are physically separated from one another, but are connected through the methods of advanced information technologies. Scientists suggest to promote these methods as they develop students' critical and creative thinking and are more motivated to study. The prevailing opinion is that when a student decides to study online, he takes maximum responsibility for the skills and abilities he needs. Thus, students learn how to learn. In addition, according to Monderna \& Voinarovska (2019), it is essential to comply the following conditions in order to enhance the efficiency and productivity of a person's activity: multiplicity of motives within a definite field of activity, level of their advancement, positive attitude towards the process, stability and power of the motives, and hierarchy structure of the motivation.

Scientists have demonstrated the dominance of autonomy and, as a consequence, independence of students in e-learning (Mehrdad et al., 2011). Criteria such as self-determination and independence lead to a process of learning enjoyment while increasing the effectiveness in achieving goals.

Today forms of e-learning are diverse. Innovations in the sphere of technological progress gradually improve and renew the existing e-learning forms. The process of digitalization is constantly adding new forms and, as a result, methods to electronic teaching. These forms include web-based learning, webinars or virtual classrooms, video-based, collaborative, custom and mobilelearning. We consider all the existing e-learning forms could be classified as person-oriented and group-oriented ones. Web-based form, video-based learning and mobile e-learning belong to the person-oriented group according to our classification, while virtual classrooms, collaborative learning and custom elearning belong to the group-oriented one. Person-oriented group of e-learning forms does not include on-line interactivity but group-oriented forms are closely connected with the interactive component within the process of e-learning.

Web-based form of learning can be accessed via web browsers. Its main advantage is the possibility for learners to organize the process at their own pace. Personal tempo and mode are formed within the set time. Moreover, the educational process can take place almost everywhere, including home place and there is no necessity to be present at the training centre. Today the web-based form of learning is popular enough and considered to be a user-friendly medium. At the same time it's necessary to note it may need special bandwidth and software and systematic self-organization as well. In fact, some people prefer to learn "alive" among students and having a teacher in front of them. 
This fact has led to the creation of virtual classrooms as another form of elearning. A virtual classroom is similar to a traditional classroom, except that the teacher and students login virtually from different places. One of the forms of such an actual learning is webinars. It's delivered through video conferencing software and can be a training session or workshop.

Another form of modern e-learning is video-based learning. No doubt videos are useful in learning as they are bright, rich in graphics and very informative. As well they can keep human attention for a long period of time. Psychological analyses prove videos can be processed by human brains many times quicker than text as they don't demand as much imagination as simple texts (Margalit, 2017). Bright scenes and pictures are already present in videos so learners just have to accept them in the ready-made state. Videos can include animations, documented case-studies, interviews and testimonials of experts, or screencast recording. Like web-based learning videos can be watched from anywhere and rewatched as many times as learners need.

In the everyday life more and more people prefer to get information from video sources. Therefore video-based learning must become an integral part of education today. Video is the best way to make people share and interact with content since they get involved quickly. So, to our mind, videos are always good to begin with. For instance, every new unit in e-learning process could be started with watching a video containing new topical material.

Being one of the most impactful ways to speak to the audience printed information can't get substituted fully by video e-learning. According to psychologists, while reading an article people don't just look at the words in front of them but create thoughts about that content, activating their mental structures (Margalit, 2017).

Thus, watching and reading are two contrary psychological processes, i.e. passive and active. This fact makes us come to the conclusion that videos can't be the only form of e-learning as this way learners do not get activated which is actually of paramount importance by any type of learning.

Another well-known form of e-learning is collaborative learning based on the interaction. Students interact with each other, their teacher or other experts who can help in special fields of science. Discussions, brain-storming, disputes like "pros and cons" can be organized due to the possibilities of chats, messengers, etc. Collaborative form of learning is the best way to share fresh ideas, to find new perspectives, to start innovations, to find out advantages and disadvantages. Collaborative learning makes learners think and be active. To our mind, such form of learning is the easiest and powerful way to improve knowledge and make it perfect. Today social media platforms like Facebook, Twitter, Instagram, etc. can help to organize collaborative e-learning. 
Havryliuk et al., 2020. Implementation of E-Learning as an Integral Part of the Educational Process

Time changes the demands to e-learning content and knowledge of elearners. In addition, different companies have different demands for future employees. Yet as well training should be aligned with learners' specific needs. These facts have originated custom e-learning in the way of special training courses for the target audience. Michael Allen, a well-known author, argues that custom e-learning courses have content that is carefully curated to address learning objectives, which fill the performance gaps of learners. The process of custom e-learning development includes the collaboration and combined efforts of different experts such as instructional designers, authoring tool experts, subject matter experts, and a lot of careful planning and project management to facilitate the development of learner-centric courses (Omer, 2019). Many organizations create in-house teams for developing such courses. As for the above mentioned we conclude this form is closely interrelated with micro e-learning allowing learners to focus on specific information.

Smartphones and other mobile devices have changed our life and brought to life mobile e-learning as a part of the educational process. Accessibility of any information due to mobile devices makes life mobile and flexible. For many learners who are constantly on the run it becomes the best and often the only way to learn. For the young generation mobile devices are an essential and integral part of their lives. This fact has made mobile learning an independent online learning format.

Taking into consideration the information about the existing forms of elearning we come to the conclusion that every form has its advantages and disadvantages. Nevertheless each form can be a good addition to other forms. Therefore to make e-learning process integral and diverse teachers have to combine different e-learning forms: person-oriented forms have to be closely connected with group-oriented ones.

Classification of e-learning tools according to the main activities can be the basis for identifying the most impacted Quality Score Groups for the formation of certain types of educational competences. This is a must for determining whether said software contributes to the formation required types of student learning competencies. In turn, it could be an important step towards identifying adequate quality metrics the use of these tools, which will allow the development of more efficient quality assessment techniques, providing guidance on more appropriate paths in selection and use of e-learning tools and methods (Evans et al., 2019).

Depending on the specific objectives of the e-learning in general and aims of its separate units one or several e-learning forms can be leading and dominant. This mix is known as blended learning. To our mind blended e-learning is the best way to introduce education distantly with the help of electronic devices as it makes the process of learning diverse, polyhedral and thus not monotonous and boring. 
The e-learning methods are predetermined by its forms. The most general of them include synchronous and asynchronous e-learning methods.

According to Soni (2015), synchronous events are those that happen in real time. To provide synchronous communication between two people, both of them must be present at a given time. Widely used examples of synchronous e-learning are chats, video and audio conferences, live webcasting, application sharing, whiteboard, polling, and virtual classrooms. Asynchronous e-learning is not timedependent since it can be performed at any time. Popular examples of asynchronous e-communication are the discussion forums and e-mail. Asynchronous e-learning let the students master the course at their own pace coming back to the previous studied information any time thy need and revising the material as many times as a person requires. Examples of practical implementation of asynchronous e-learning are audio/video, E-mail, discussion forum, Wiki/Blog, Webcasting/Conferencing, CBT and WBT, Simulations, Game-based learning, etc. (Soni, 2015).

We consider blended e-learning to be the best techniques both in terms of its forms and methods. Proper combination of synchronous and asynchronous elearning methods depends on the target audience. Thus, children audience needs mostly synchronous learning while adult audience goes on well enough with asynchronous methods. Four basic methods in e-learning which are simple enough and can suit any audience have been distinguished (Hyla, 2015). They are "workbook method", "the method of tours", "repetition” and "note-taking”.

Workbook structure and function remains the same: to practice fresh knowledge through exercises but it can become improved due to possibilities of electronic devices today. Hyla (2015) suggests there should be built an easy-todifficult practicing path based on consequent steps with highly interactive (yet easy to use and well explained) exercises. The exercises can be made visually appealing and fun and astonish trainees with every single screen. It is considered a good idea to create an e-learning course mostly based on exercises.

Another method is to organize virtual tours to historical sites (castles, battlegrounds), biosphere sites (botanical gardens, forests, mountains), various museums, etc. These tours can be a great experience when combined with storytelling (by a guide or a teacher).

Repetition is one of the most important methods as according to Hermann Ebbinghaus' Forgetting Curve theory (Pappas, 2014) all people have to repeat in order to remember things and routines. If we do not do this, the vast majority of new information will disappear during the first 24 hours of the learning process. So, every portion of information needs "coming back" and repetition. Students can be suggested to print out cheat-sheets, check-lists, visuals, mind-maps, etc. Every such activity becomes additional stimulus to revise material. 
Havryliuk et al., 2020. Implementation of E-Learning as an Integral Part of the Educational Process

Note-taking is also important as it allows students to put information into their personal context by paraphrasing it, arranging it in individual structures, or connecting it with individual experiences. In e-learning students can use special options for taking notes or marking informative fragments. In our opinion, mind maps can help the best way in summarizing every module of e-learning course.

Distance learning course "Business Foreign Language" was developed on the basis of the Internet platform Moodle for carrying out individual work by future interpreters. This course enables the students to look through all the materials that the teacher provides during the classes throughout the study; print it, if necessary; do homework and work independently, etc.

The distance learning course "Business Foreign Language" aims to form foreign language communicative, informational, professional and cognitive competence of students and the ability to use business terminology for academic and professional needs, to develop skills of oral (dialogical and monologic) speech, writing, functional reading, skills of writing abstracts, etc. The distance course is divided into separate sections, which contain the following components: methodical guidelines for the course; video and audio materials; curriculum of the course "Business Foreign Language"; thematic plans and grading criteria; list of recommended literature, glossary; plans and tasks for practical classes; tests; methodical guidelines and individual assignments; tests for self-control; program questions for the exam; grammar tasks; multimedia course materials, etc.

Web-quest technology has been used an effective methods of forming foreign-language communicative competence necessary for further professional activities of future specialists. Web-quests have enables the students to develop such competences as making social role choices, skills of teamwork, ability to think creatively, etc. The main purpose of the web-quest is to provide students with practical skills and knowledge that they need in real life conditions as well as to form such indicators of competence as the internal motivation to creative self-realization; knowledge in the field of translation studies, economics, tourism, management, business, knowledge of management technology; speed, flexibility, originality, associativity of thinking; possession of techniques for generating and analyzing ideas, initiative in activities; the ability to influence subordinates, contact; basic managerial skills, experience of creative activity.

In the course of teaching "Business English" to students, we have widely used the most common interactive methods in professional education, e.g. brainstorming, the method of prediction or forecasting, PRES-method, etc.

Another important aspect in the formation of foreign language competence is the use of information and communication technologies, the work with computer and multimedia educational programs, the distance learning technologies in foreign languages, the creation of presentations in the Microsoft Power Point, the usage of World Wide Web resources. 


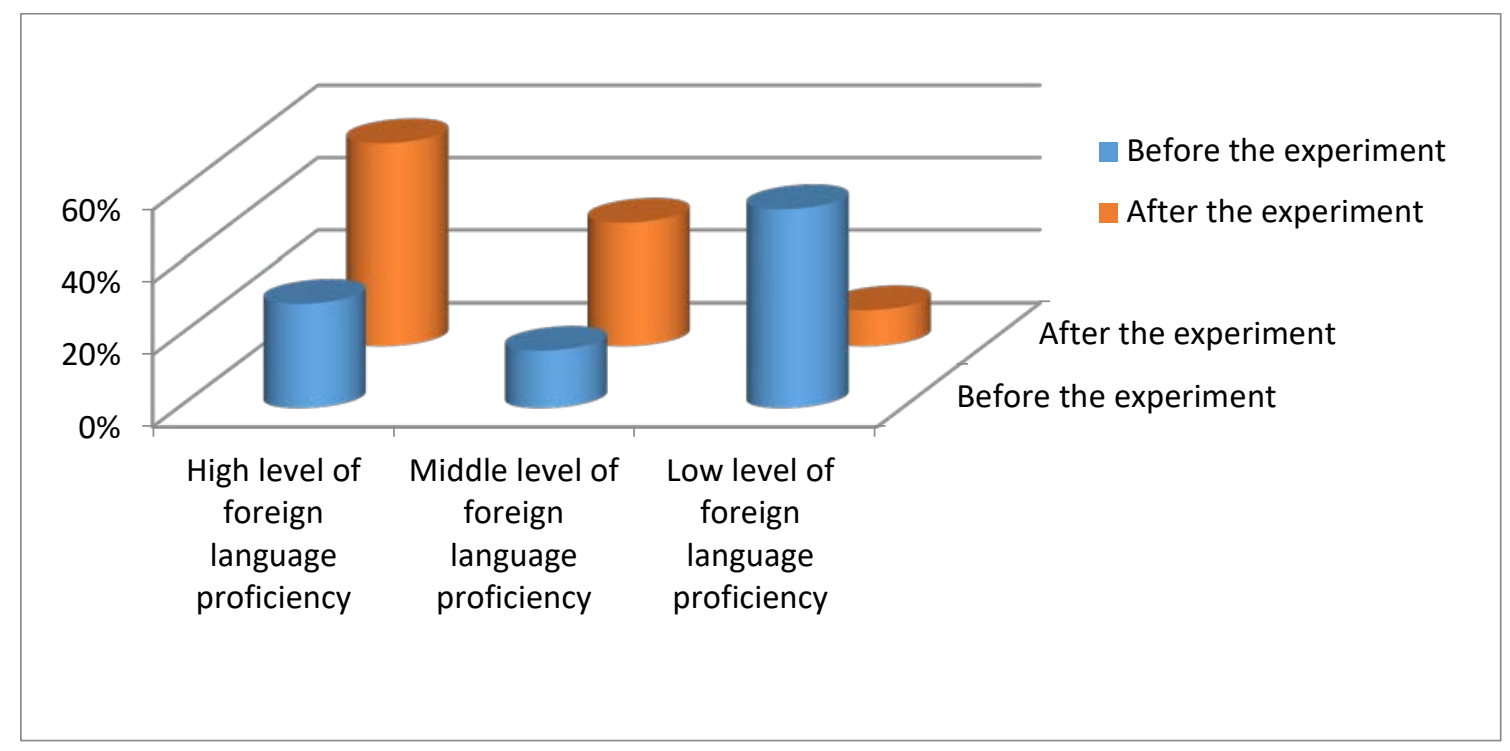

Figure 1 Comparative analysis of foreign language proficiency of students

The diagram (Fig. 1) shows academic performance of students before and after implementation of e-learning approach for the development of foreign language proficiency achieved when learning "Business Foreign Language". According to the results of control assignments, e-learning practices have improved foreign language competence of students, especially lexical competence, when doing the tasks, watching video, listening to the audio, etc. suggested by the lecturer through their access to the lecturer's e-course presented in the electronic system of the University.

In addition, our survey has revealed much higher interest of students in learning. Availability of on-line tests on the topics studied let the students conduct self-control and evaluate their progress. Free access to different types of assignments ensured implementation of the individualized approach as well as extra-curricular activities of students since every e-course offers the tasks for both additional and individual wok of students. This motivates the students to make their own choices and get extra grades for some additional activities.

\section{Conclusions}

Within our investigation it has been concluded that e-learning is an effective and innovative educational technology that can improve the process of teaching "Business Foreign Language” to University students. Distributing e-learning via a computer network provides access to the information necessary for students to acquire professional skills, increase their interest in learning English and improves foreign language proficiency, realize cognitive and creative potential of students. 
Havryliuk et al., 2020. Implementation of E-Learning as an Integral Part of the Educational Process

Implementation of innovative pedagogical technologies and methods at the foreign language classes have increased foreign language proficiency of students, let us involve all the group into active work, provided the best conditions for gaining listening and reading skills, increased motivation for learning, promoted personal development of students, made the teaching process student-centered.

E-learning forms can be classified into person-oriented and group-oriented ones and used depending on the target audience and particular objectives of the class. Blended e-learning is treated as the most effective and farsighted method among e-learning practices.

\section{References}

Abbad, M.M., Morris, D., \& Nahlik, C. (2009). Looking under the Bonnet: Factors Affecting Student Adoption of E-Learning Systems in Jordan. International Review of Research in Open and Distance Learning, 10(2). Retrieved from https://pdfs.semanticscholar.org/ 120b/55e112ed08cbb8b99dbf02bc95a226c0ffb9.pdf?_ga=2.219943257.159190740.157 8785361-375751667.1578785361

Amit, S. (2015). Choosing the right e-learning methods: factors and elements. E-learning industry. Retrieved from https://elearningindustry.com/

Dewey, B., \& DeBlois, P. (2006). Top Ten IT Issues. EDUCAUSE Review, 41(3), 58-79.

Evans, J.C., Yip, H., Chan, K., Armatas, C., \& Tse A. (2019). Blended learning in higher education: professional development in a Hong Kong university. Journal Higher Education Research \& Development. DOI: doi.org/10.1080/07294360.2019.1685943

Hyla, M. (2015). 4 basic learning methods in e-learning. E-learning Industry, June 22. Retrieved from https://elearningindustry.com/

Jennex, M.E. (2005). Case Studies in Knowledge Management. Idea Group Publishing: Hersley.

Kostikova, I. (2015). Elektronna pedahohika: monohrahiia. Kharkiv: "Smuhasta typohrafiia".

Liaw, S.S., \& Huang, H.M. (2003). Exploring the World Wide Web for Online Learning: A Perspective from Taiwan. Educational Technology, 40(3), 27-32.

Liu, Y., \& Wang, H. (2009). A comparative study on e-learning technologies and products: from the East to the West. Systems Research \& Behavioral Science, 26(2), 191-209.

Margalit, L. (2017). Video vs. Text: The Brain Perspective. Psychology Today, July 13. Retrieved from http://wondermouse.us/blog-post/blog-test-1/

Mehrdad, N., Zolfaghari, M., Bahrani, N., \& Eybpoosh, S. (2011). Learning Outcomes in Two Different Teaching Approach in Nursing Education in Iran: E-Learning versus Lecture. Acta Medica Iranica, 49(5), 296-301. Retrieved from http://acta.tums.ac.ir/ index.php/acta/article/view/3743

Oblinger, D.G., \& Hawkins, B.L. (2005). The myth about E-learning. EDUCAUSE Review, 40(4), 14-15.

Omer, A.H. (2019). Excellent Reasons To Outsource Custom eLearning Development September 2. Retrieved from https://elearningindustry.com/

Pappas, C. (2014). The Forgetting Curve in eLearning: What eLearning Professionals Should Know. E-learning Industry, December 31. Retrieved from https://elearningindustry.com/ forgetting-curve-in-elearning-what-elearning-professionals-should-know 
Simuth, J., \& Sarmany-Schuller, I. (2012). Principles for e-pedagogy. Procedia - Social and Behavioral Sciences, 46. 4454-4456.

Somayeh, M., Dehghani, M., Mozaffari, F., Ghasemnegad, S.M., Hakimi, H., \& Samaneh, B. (2016). The effectiveness of E- learning in learning: A review of the literature. International Journal of Medical Research \& Health Sciences, 5(2), 86-91.

Soni, M. (2015). Choosing The Right eLearning Methods: Factors and Elements. E-learning Industry, May 24. Retrieved from https://elearningindustry.com/choosing-rightelearning-methods-factors-elements

Tao, Y.H., Yeh, C.R., \& Sun, S.I. (2006). Improving training needs assessment processes via the Internet: system design and qualitative study. Internet Research, 16(4), 427-449.

Tibaná-Herrera, G., Fernández-Bajón, M.T., \& De Moya-Anegón, F. (2018). Categorization of E-learning as an emerging discipline in the world publication system: a bibliometric study in SCOPUS. International Journal of Educational Technology in Higher Education, 15:21. DOI: doi.org/10.1186/s41239-018-0103-4 